\title{
Autonomic abnormalities demonstrable in young normotensive subjects who are children of hypertensive parents
}

\footnotetext{
H.F. Lopes, H.B. Silva,

F.M. Consolim-Colombo, J.A.S. Barreto Filho,

G.M.G. Riccio, D.M.A. Giorgi and E.M. Krieger
}

Unidade de Hipertensão, Instituto do Coração, Faculdade de Medicina, U niversidade de São Paulo, São Paulo, SP, Brasil

\section{Correspondence \\ H.F. Lopes \\ Unidade de Hipertensão INCOR, FM, USP \\ Av. Eneas de Carvalho Aguiar, 44 05404-000 São Paulo, SP Brasil \\ Fax: + 55-11-3069-5048 \\ E-mail: hipheno@incor4.incor.usp.br}

Research supported by the E.J. Zerbini Foundation. Publication supported by FAPESP

Received June 17, 1999 Accepted O ctober 19, 1999

\section{Abstract}

Although a slightly elevated office blood pressure (BP) has been reported in several studies, little is known about the prolonged resting blood pressure, heart rate (HR) and baroreflex sensitivity (BRS) of prehypertensive subjects with a family history of hypertension. Office blood pressure, prolonged resting $(1 \mathrm{~h}) \mathrm{BP}$ and HR were measured in 25 young normotensives with a positive family history of hypertension $(\mathrm{FH}+)$ and 25 young normotensives with a negative family history of hypertension (FH-), matched for age, sex, and body mass index. After BP and HR measurements, blood samples were collected for the determination of norepinephrine, plasma renin activity and aldosterone levels, and baroreflex sensitivity was then tested. Casual BP, prolonged resting $\mathrm{BP}$ and heart rate were significantly higher in the $\mathrm{FH}+$ group $(119.9 \pm 11.7 / 78.5 \pm 8.6 \mathrm{mmHg}, 137.3 \pm 12.3 / 74.4 \pm 7.9$ $\mathrm{mmHg}, 68.5 \pm 8.4 \mathrm{bpm})$ compared to the FH- group $(112.9 \pm 11.4 / 71.2$ $\pm 8.3 \mathrm{mmHg}, 128.0 \pm 11.8 / 66.5 \pm 7.4 \mathrm{mmHg}, 62.1 \pm 6.0 \mathrm{bpm})$. Plasma norepinephrine level was significantly higher in the $\mathrm{FH}+$ group (220.1 $\pm 104.5 \mathrm{pg} / \mathrm{ml})$ than in the $\mathrm{FH}$-group $(169.1 \pm 63.3 \mathrm{pg} / \mathrm{ml})$. Baroreflex sensitivity to tachycardia $(0.7 \pm 0.3 v s 1.0 \pm 0.5 \mathrm{bpm} / \mathrm{mmHg})$ was depressed in the $\mathrm{FH}+$ group $(\mathrm{P}<0.05)$. The $\mathrm{FH}+$ group exhibited higher casual blood pressure, prolonged resting blood pressure, heart rate and plasma norepinephrine levels than the FH- group $(\mathrm{P}<0.05)$, suggesting an increased sympathetic tone in these subjects. The reflex tachycardia was depressed in the $\mathrm{FH}+$ group.

\section{Introduction}

In a previous study (1), we demonstrated that young normotensives with a positive family history of hypertension $(\mathrm{FH}+)$ have higher total cholesterol, LDL-cholesterol, VLDL-cholesterol and triglyceride levels, as well as higher office blood pressure when compared with young normotensives with a

\section{Key words}

- Heart rate

- Blood pressure

- Baroreflex sensitivity

- Family history of

hypertension negative family history of hypertension (FH-). A slightly elevated office blood pressure in normotensive subjects with a family history of parental hypertension has been reported (2-4). This blood pressure elevation may be considered as a permanent abnormality characterizing a prehypertensive stage early in life $(1,5)$. Since white-coat hypertension may be present in this population, a 
prolonged resting continuous blood pressure measurement in the absence of a doctor or nurse may be useful to better characterize the blood pressure behavior of this population. Increased sympathetic activity may be a possible mechanism for alterations in blood pressure regulation (6). Blood pressure regulation largely depends on baroreflex function, but the reflex tachycardia by nitroglycerine injection has not yet been studied in subjects with a family history of parental hypertension. The goal of the present study was to evaluate the prolonged resting heart rate, blood pressure, norepinephrine level and baroreflex sensitivity (BRS) of young normotensives with a positive family history of hypertension.

\section{Material and Methods}

Twenty-five young normotensives with a positive family history of hypertension $(\mathrm{FH}+$ ) and 25 young normotensives with a negative family history of hypertension (FH-) were included in this study. They were healthy normotensive medical students whose office blood pressure was less than 140/90 $\mathrm{mmHg}$ on two different occasions. The parents with a positive or negative history of hypertension were identified by evidence of antihypertensive treatment in their medical records or by direct blood pressure measurements. A positive family history of hypertension was considered to be present when at least one of the parents was hypertensive. The groups with $\mathrm{FH}+$ and $\mathrm{FH}-$ were matched for age, gender, race and body mass index (Table 1).

Table 1 - Age, gender, race and body mass index (BMI) of the subjects studied.

\begin{tabular}{lcc}
\hline Variables & $\begin{array}{c}\text { Negative family history of } \\
\text { hypertension }(\mathrm{N}=25)\end{array}$ & $\begin{array}{c}\text { Positive family history of } \\
\text { hypertension }(\mathrm{N}=25)\end{array}$ \\
\hline Age (years) & $20.9 \pm 2.1$ & $20 \pm 1.5$ \\
Gender & 16 males, 9 females & 18 males, 7 females \\
Race & 18 whites, 7 orientals & 20 whites, 5 orientals \\
BMI, $\mathrm{kg} / \mathrm{m}^{2}$ & $22.1 \pm 2.1$ & $22 \pm 2.2$
\end{tabular}

After an overnight fast, subjects were admitted to the laboratory and continuous arterial blood pressure was measured noninvasively using the Finapres finger-cuff method for one hour in the supine position (baseline measurements). Blood samples were then collected for measurements of noradrenaline by high performance liquid chromatography, and of plasma renin activity and aldosterone levels by radioimmunoassay. After blood pressure and heart rate recovery, BRS to unloading of the baroreceptors was evaluated by recording cardiac acceleration in response to nitroglycerin-induced fall in blood pressure. BRS to loading of the baroreceptors was evaluated by recording cardiac slowing in response to acute hypertension induced by phenylephrine (bolus of $100 \mu \mathrm{g}$ ). Baroreflex slopes were calculated by plotting the heart rate (bpm) against the preceding peak systolic arterial pressure $(\mathrm{mmHg})$.

Results are reported as means \pm SD. Data concerning categorical variables (gender, race) were analyzed by the chi-square test. The intergroup differences in mean values were assessed by the Student $t$-test. A value of $\mathrm{P}<0.05$ was taken as the level of statistical significance. All participants signed an informed consent approved by the Ethical Committee from the Hospital das Clínicas, University of São Paulo.

\section{Results}

Mean office blood pressure, resting continuous arterial blood pressure and heart rate measured noninvasively by the Finapres finger-cuff method were higher in the offspring of hypertensive families than in the offspring of normotensive families (Table 2). Plasma noradrenaline was higher $(\mathrm{P}<0.05)$ in the $\mathrm{FH}+$ group $(220.1 \pm 104.5 \mathrm{pg} / \mathrm{ml})$ than in the FH- group $(169.1 \pm 63.3 \mathrm{pg} / \mathrm{ml})$. Plasma renin activity $\left(1.1 \pm 1.0\right.$ vs $1.0 \pm 0.9 \mathrm{ng} \mathrm{ml}^{-1}$ $\left.\mathrm{h}^{-1}\right)$ and aldosterone levels (10.7 \pm 2.9 vs 9.2 $\pm 3.8 \mathrm{ng} / \mathrm{ml}$ ) did not differ between the $\mathrm{FH}+$ and $\mathrm{FH}-$ groups. Baroreflex sensitivity to 
tachycardiac responses was significantly $(\mathrm{P}<0.05)$ depressed in the $\mathrm{FH}+$ group $(0.7 \pm$ $0.3 \mathrm{bpm} / \mathrm{mmHg}$ ) when compared with the $\mathrm{FH}$ - group $(1.0 \pm 0.5 \mathrm{bpm} / \mathrm{mmHg})$. Baroreflex sensitivity to bradycardiac responses $(1.1 \pm 0.5 \mathrm{bpm} / \mathrm{mmHg}$ vs $1.2 \pm 0.5 \mathrm{bpm} /$ $\mathrm{mmHg}$ ) did not differ between the $\mathrm{FH}+$ and FH- groups.

\section{Discussion}

The major finding of this study was that young normotensives with a positive family history of hypertension had not only higher office blood pressure but also increased prolonged resting heart rate and blood pressure. Elevated office blood pressure in young normotensives with a positive family history of hypertension has been frequently reported; however, the association with prolonged resting elevated systolic and diastolic blood pressures observed here is new. Indeed, we observed a difference in systolic and diastolic office blood pressures of approximately 7 $\mathrm{mmHg}$ between groups and the difference in systolic $(9 \mathrm{mmHg})$ and diastolic $(8 \mathrm{mmHg})$ blood pressures persisted during prolonged resting measurement $(1 \mathrm{~h})$. Since the differences obtained with the two methods were similar, the values provided by the Finapres method seem to reflect the real pressure values, even when inaccuracies may occur during prolonged measurement (7). The increase in blood pressure during prolonged resting suggests a true sustained elevated blood pressure, characterizing a permanent abnormality in the prehypertensive stage, rather than a white-coat hypertension reaction during casual measurement as previously thought (8). Moreover, the higher heart rate during prolonged resting, associated with a $30 \%$ increase in plasma norepinephrine levels, suggests an increased sympathetic activity in the prehypertensive stage in the group with a positive family history of hypertension. Increased norepinephrine levels, indicating an enhanced sympathetic activity, were described by Masuo et al. (9) in a longitudinal study involving young nonobese men that presented a rise $\geq 10 \%$ in blood pressure after ten years of age.

Regarding the baroreflex control heart rate, although the $\mathrm{FH}+$ subjects had a depressed tachycardiac response to nitroglycerine, they showed a normal bradycardiac response to phenylephrine. Depressed baroreflex sensitivity to bradycardia was described by Iwase et al. (10) when the phenylephrine test was used, but was not detected by Ditto and France (11) and Ravogli et al. (5), when the neck chamber method was used. Our data indicating an impairment of the baroreflex control of the tachycardia, but not of bradycardia, is somewhat unexpected, since a parasympathetic mechanism is primarily involved in baroreflex control of heart rate, while control of vascular resistance mainly reflects sympathetic activity (12). There are experimental reports in the literature $(13,14)$ indicating that the baroreflex control of the bradycardiac responses is first impaired, before attenuation of the tachycardiac responses is demonstrable. In this respect, it should be mentioned that changes in sympathetic or vagal tone alone can alter the dynamic response to vagosympathetic stimulation (15). Otherwise, if the impairment of the baroreflex control of the heart rate is secondary to a depression of the afferent component of the baroreflex pathway, usually observed in chronic hypertension $(16,17)$,

Table 2 - Casual blood pressure, prolonged resting blood pressure and heart rate of normotensive subjects.

Data are reported as means \pm SD. SBP, Systolic blood pressure; DBP, diastolic blood pressure. ${ }^{*} \mathrm{P}<0.05$ compared with control group (Student t-test).

\begin{tabular}{lcr}
\hline Variables & $\begin{array}{c}\text { Negative family history } \\
(\mathrm{N}=25)\end{array}$ & $\begin{array}{c}\text { Positive family history } \\
(\mathrm{N}=25)\end{array}$ \\
\hline Casual SBP $(\mathrm{mmHg})$ & $112.9 \pm 11.4$ & $119.9 \pm 11.7^{*}$ \\
Casual DBP $(\mathrm{mmHg})$ & $71.2 \pm 8.3$ & $78.5 \pm 8.6^{*}$ \\
Resting SBP $(\mathrm{mmHg})$ & $128.0 \pm 11.8$ & $137.3 \pm 12.3^{*}$ \\
Resting DBP $(\mathrm{mmHg})$ & $66.5 \pm 7.4$ & $74.4 \pm 7.9^{*}$ \\
Resting HR $(\mathrm{bpm})$ & $62.1 \pm 6.0$ & $68.5 \pm 8.4^{*}$
\end{tabular}


both the baroreflex-mediated bradycardia and tachycardia should be depressed. Therefore, the impairment observed here only in the tachycardiac response is more likely to depend on an alteration in the efferent pathway of the baroreflex due to a downregulation of the sympathetic system determined by its chronic overactivity. The reduced baroreflex sensitivity may also be secondary to a sympathetic pressor reflex, as demonstrated in dogs (18). To explain baroreflex alteration, it should also be mentioned that Koskinen et al. (19) observed that LDL- cholesterol level and BRS were inversely correlated. As we demonstrated before, young normotensives with $\mathrm{FH}+$ have higher total cholesterol, LDL-cholesterol, VLDL-cholesterol and triglyceride levels. In conclusion, the increased blood pressure and heart rate observed here in the offspring of hypertensive parents, associated with our previous demonstration that they also exhibit increased cholesterol and triglyceride levels, emphasize the importance of genetic influence on the prehypertensive phase of hypertension.

\section{References}

1. Lopes HF, Bernardes Silva H, ConsolimColombo FM, Barreto Fo J AS, Giorgi DMA \& Krieger EM (1997). Lipid metabolism alterations in normotensive subjects with positive family history of hypertension. Hypertension, 30 (Part 2): 629-631.

2. Ohlsson $O \&$ Henningsen NC (1982). Blood pressure, cardiac output and systemic vascular resistance during rest, muscle work, cold pressure test and psychological stress. Acta Medica Scandinavica, 212: 329-336.

3. Mcllhany ML, Shafer JW \& Hines J r EA (1975). The heritability of blood pressure: An investigation of 200 pairs of twins using cold pressure test. J ohns Hopkins Medical J ournal, 136: 57-64.

4. Ostfeld AM \& Oglesby P (1963). The inheritance of hypertension. Lancet, 1: 575579.

5. Ravogli A, Trazzi S, Villani A, Mutti E, Cuspidi C, Sampieri L, De Ambroggi L, Parati G, Zanchetti A \& Mancia G (1990). Early 24-hour blood pressure elevation in normotensive subjects with parental hypertension. Hypertension, 16: 491-497.

6. J ulius S \& Nesbitt S (1996). Sympathetic overactivity in hypertension. A moving target. American J ournal of Hypertension, 9: 113S-120S.

7. Ristuccia HL, Grossman P, Waktkins LL \& Lown B (1997). Incremental bias in Finapres estimation of baseline blood pressure levels over time. Hypertension, 29:
1039-1043.

8. Hornsby J L, Mongan PF, Taylor AT \& Treiber FA (1991). "White coat" hypertension in children. J ournal of Family Practice, 33: 617-623.

9. Masuo K, Mikami H, Ogihara T\& Tuck ML (1998). Familial hypertension, insulin, sympathetic activity, and blood pressure elevation. Hypertension, 32: 96-100.

10. Iwase N, Takata S, Okuwa H, Ogawa J, Ikeda T \& Hattori N (1984). Abnormal baroreflex control of heart rate in normotensive young subjects with a family history of essential hypertension. J ournal of Hypertension, 2: S-409-S-411.

11. Ditto B \& France C (1990). Carotid baroreflex sensitivity at rest and during psychological stress in offspring of hypertensives and non-twin sibling pairs. Psychosomatic Medicine, 52: 610-620.

12. Mancia G\& Mark AL (1983). Cardiopulmonary baroreflex in humans. In: Shepherd JT \& Abboud FM (Editors), Handbook of Physiology: The Cardiovascular System. Peripheral Circulation and Organ Blood Flow. Vol. III. American Physiology Society, Washington, DC, 795-813.

13. Head GA \& Adams MA (1992). Characterization of the baroreceptor heart rate reflex during development in spontaneously hypertensive rats. Clinical and Experimental Pharmacology and Physiology, 19: 587597.

14. Whitescarver AS, Ott CE \& Kotchen TA
(1990). Parasympathetic impairment of baroreflex control of heart rate in Dahl S rats. American J ournal of Physiology, 259 (Part 2): R76-R83.

15. Kawada $T$, Sugimachi $M$, Shishido $T$, Miyano H, Sato T, Yoshimura R, Miyashita $\mathrm{H}$, Nakahara T, AlexanderJ rJ \& Sunagawa K (1999). Simultaneous identification of static and dynamic vagosympathetic interactions in regulating heart rate. American J ournal of Physiology, 276 (Regulatory, Integrative and Comparative Physiology, 45): R782-R789.

16. Bristow J D, Honour AJ, Pickering GW, Sleight P \& Smyth HS (1969). Diminished baroreflex sensitivity in high blood pressure. Circulation, 39: 48-54.

17. Mancia G, LudbrookJ , Ferrari A, Gregorini L \& Zanchetti A (1978). Baroreceptor reflexes in human hypertension. Circulation Research, 43: 170-177.

18. Pagani $M$, Pizzinelli $P$, Bergamaschi $M \&$ Malliani A (1982). A positive feedback sympathetic pressor reflex during stretch of the thoracic aorta in conscious dogs. Circulation Research, 50: 125-132.

19. Koskinen $P$, Kupari $M$, Virolainen J, Stjernvall J , J olkkonen J , Tuomilehto J \& Tikkanen MJ (1995). Heart rate and blood pressure variability and baroreflex sensitivity in normotense with hypercholesterolaemia. Clinical Physiology, 15: 483489. 